\title{
'I try my best ... I try to relieve the burden of my mum': a narrative analysis of the everyday caregiving experiences for five intergenerational Singapore-Chinese families where one member has dementia
}

DOI:

$10.1017 / S 0144686$ X20000070

\section{Document Version}

Accepted author manuscript

Link to publication record in Manchester Research Explorer

\section{Citation for published version (APA):}

Koo, M. Y., Pusey, H., \& Keady, J. (2020). 'I try my best ... I try to relieve the burden of my mum': a narrative analysis of the everyday caregiving experiences for five intergenerational Singapore-Chinese families where one member has dementia. Ageing and Society. https://doi.org/10.1017/S0144686X20000070

\section{Published in:}

Ageing and Society

\section{Citing this paper}

Please note that where the full-text provided on Manchester Research Explorer is the Author Accepted Manuscript or Proof version this may differ from the final Published version. If citing, it is advised that you check and use the publisher's definitive version.

\section{General rights}

Copyright and moral rights for the publications made accessible in the Research Explorer are retained by the authors and/or other copyright owners and it is a condition of accessing publications that users recognise and abide by the legal requirements associated with these rights.

\section{Takedown policy}

If you believe that this document breaches copyright please refer to the University of Manchester's Takedown Procedures [http://man.ac.uk/04Y6Bo] or contact uml.scholarlycommunications@manchester.ac.uk providing relevant details, so we can investigate your claim.

\section{OPEN ACCESS}




\section{AgeING \& Society}

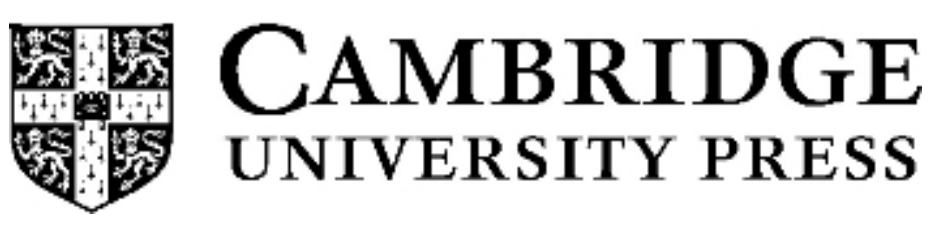

'I try my best ... I try to relieve the burden of my mum': A narrative analysis of the everyday caregiving experiences for five intergenerational Singapore-Chinese families where one member has a dementia

\begin{tabular}{|r|l|}
\hline Journal: & Ageing \& Society \\
\hline Manuscript ID & AGE-18-0427.R2 \\
\hline Manuscript Type: & Article \\
\hline Keywords: & $\begin{array}{l}\text { dementia, intergenerational, Singapore-Chinese families, family } \\
\text { connections, narrative analysis, caregiving, longitudinal qualitative } \\
\text { study, case study }\end{array}$ \\
\hline \multicolumn{2}{|l}{} \\
\hline
\end{tabular}


Corrections Table: Manuscript ID AGE-18-0427

\begin{tabular}{|c|c|}
\hline Review Requirements & Response \\
\hline Editors Comments & Authors' comments \\
\hline $\begin{array}{l}\text { Thank you for sending your revised paper to } \\
\text { Ageing \& Society, and for your efforts in } \\
\text { revising it. I have received comments from the } \\
\text { two original referees. You will see that although } \\
\text { both referees are broadly happy with the } \\
\text { revisions, both encourage you to make the paper } \\
\text { more succinct and focus on the salient points. I } \\
\text { agree with the referees' comments. } \\
\text { As such, I invite you to make further minor } \\
\text { revisions and resubmit the paper. As before, I } \\
\text { hope you are able to undertake these revisions } \\
\text { and if you do, please send an accompanying note } \\
\text { outlining how you have addressed the } \\
\text { comments. Please ensure also that the paper } \\
\text { does not exceed the stipulated length. Please } \\
\text { also check carefully that the citation style both } \\
\text { in the text and in the list of references conforms } \\
\text { to the requirements of the journal, and that the } \\
\text { list of references accurately corresponds to the } \\
\text { references used in the text. Please make the } \\
\text { following minor stylistic changes to the } \\
\text { references: } \\
\text { a) All dates should be in parenthesis in the list } \\
\text { of authors } \\
\text { b) Please remove all journal issue numbers }\end{array}$ & $\begin{array}{l}\text { - Minor revisions have been done } \\
\text { (removal of relevant texts as } \\
\text { indicated in the respective rows in } \\
\text { the table to the respective } \\
\text { reviewers; with amendments in } \\
\text { green coloured texts in the revised } \\
\text { manuscript). } \\
\text { - The total word count for this } \\
\text { manuscript is now } 8,642 \text { words } \\
\text { - Have done careful checks to } \\
\text { ensure that the citation style in the } \\
\text { text and list of references } \\
\text { conforms to the requirements of } \\
\text { the journal, and that the list of } \\
\text { references accurately corresponds } \\
\text { to the references used in the text. } \\
\text { - All dates are in parenthesis in the } \\
\text { list of authors. } \\
\text { May I clarify about the need to } \\
\text { "remove all journal issue } \\
\text { numbers"? I have checked the } \\
\text { publication instructions and am } \\
\text { perplexed by the matter which I } \\
\text { have found to be most unusual. } \\
\text { Would like to seek more clarity } \\
\text { here. }\end{array}$ \\
\hline \multicolumn{2}{|l|}{ Reviewer: 1} \\
\hline $\begin{array}{l}\text { The authors do have made some changes but I } \\
\text { do still have the below concerns The } \\
\text { introduction is too long mainly because the } \\
\text { studies have been described at length. It could } \\
\text { definitely be made more succinct and critical } \\
\text { through highlighting salient findings. }\end{array}$ & $\begin{array}{l}\text { This has now been done and incidental } \\
\text { detail has now been omitted from the } \\
\text { introduction and literature review at the } \\
\text { start of the article. } \\
\text { Please note that the following details have } \\
\text { been removed. } \\
\text { - Last para in page } 8 \text { and para } 1 \text { in page } \\
\text { 9: As an illustration of this } \\
\text { complexity, Rolland's (2012) system- } \\
\text { based, biopsychosocial model on } \\
\text { family systems broadly defined the } \\
\text { 'family' as all persons involved in the } \\
\text { family unit and caregiving, but it did } \\
\text { not clearly include members outside } \\
\text { the immediate family. However, } \\
\text { where literature exists on multiple } \\
\text { intergenerational perspectives on }\end{array}$ \\
\hline
\end{tabular}




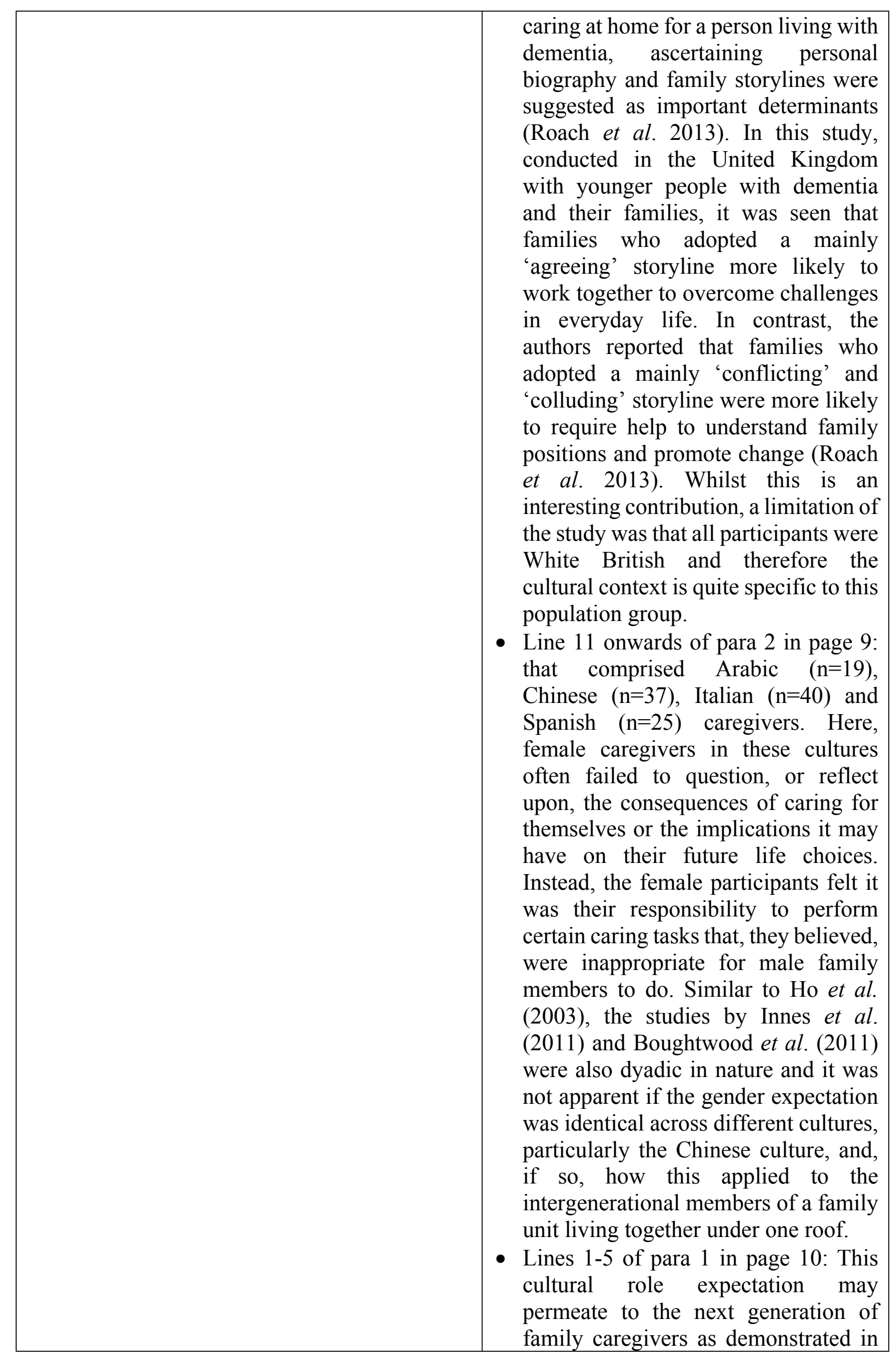




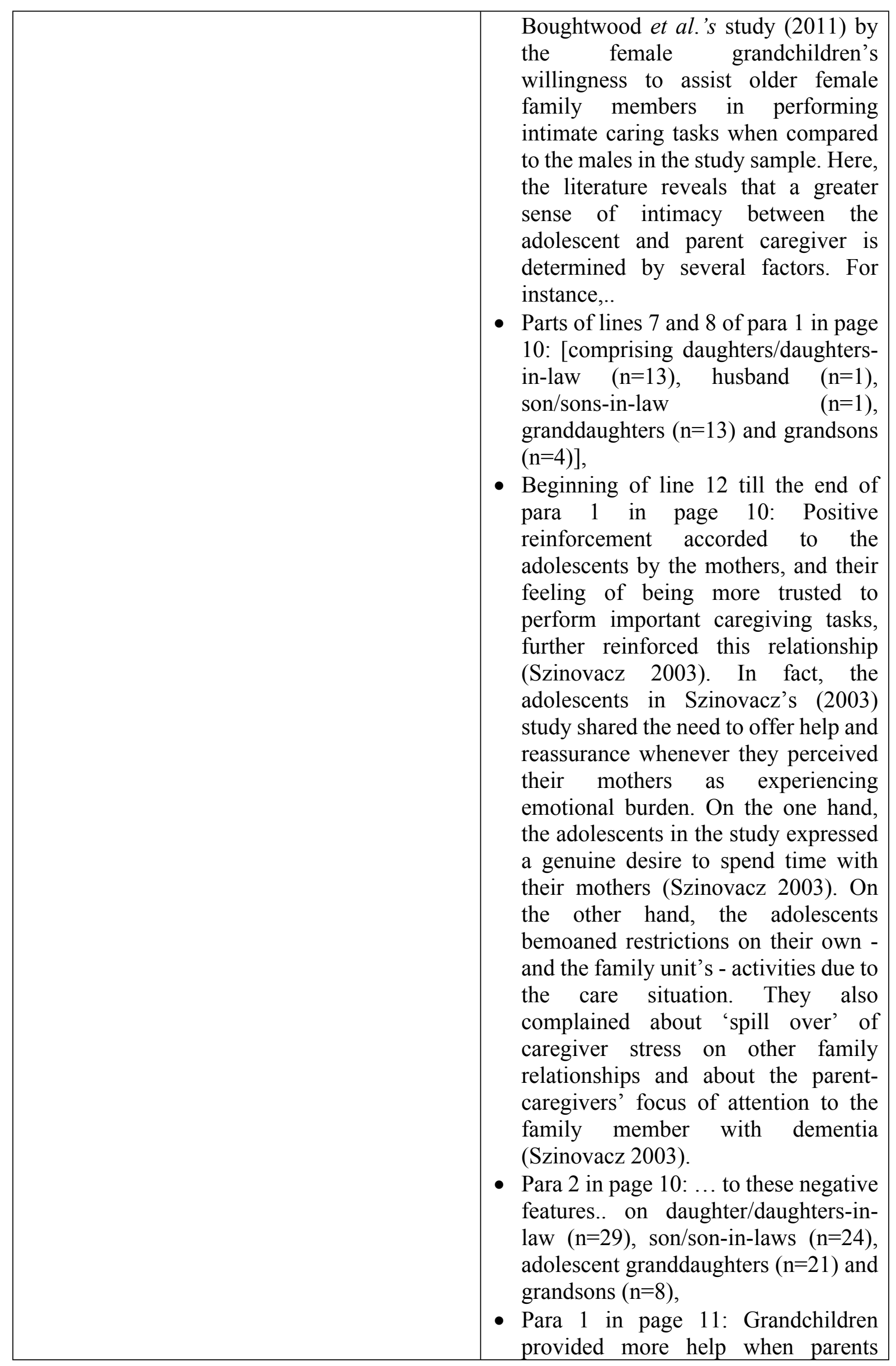




\begin{tabular}{|c|c|}
\hline & $\begin{array}{l}\text { provided more care and when } \\
\text { grandchildren had greater affection for } \\
\text { grandparents. Adolescent } \\
\text { grandchildren exhibited lower levels } \\
\text { of social responsibility and more } \\
\text { negative attitudes toward the provision } \\
\text { of long-term care when fathers } \\
\text { experienced higher subjective burden. }\end{array}$ \\
\hline $\begin{array}{l}\text { Page } 8 \text {..In addition, the carers in Ho et al's } \\
\text { (2003) study would, in all likelihood, be } \\
\text { Westernised and assimilated into Western } \\
\text { culture. } \\
\text { The above is a sweeping statement. It need not } \\
\text { necessarily be. }\end{array}$ & $\begin{array}{l}\text { Agreed and this sweeping statement has } \\
\text { now been deleted in the second } \\
\text { resubmission. }\end{array}$ \\
\hline \multicolumn{2}{|l|}{ Reviewer: 2} \\
\hline $\begin{array}{l}\text { Thank you for this revised manuscript and also } \\
\text { for clear responses to suggested revisions. The } \\
\text { Findings section is much improved with } \\
\text { additional verbatim, participant quotes, these } \\
\text { richly illustrating the three themes and the } \\
\text { commonalities and differences within and } \\
\text { across the case study presentation. }\end{array}$ & Thank you, we appreciate the comments. \\
\hline $\begin{array}{l}\text { I still respectfully suggest that both the } \\
\text { Background and Methodology sections are } \\
\text { overlong for journal article readership. As noted } \\
\text { before, there is some excellent background } \\
\text { detail and good critique of the literature } \\
\text { on intergenerational family households, but I } \\
\text { still had to work hard to distil the salient points. } \\
\text { Whilst it is good practice to be transparent about } \\
\text { methodology and methods and the case study } \\
\text { narrative framework is well described, I would } \\
\text { still urge a little bit or pruning, particularly the } \\
\text { data analysis section. } \\
\text { With some minor editing, I would welcome } \\
\text { seeing this article in print and suggest it is an } \\
\text { insightful and situated case study, that should } \\
\text { engender a lively debate about needing more } \\
\text { nuanced and contextualised understanding of } \\
\text { what is meant by 'family care'. }\end{array}$ & $\begin{array}{l}\text { The background and introduction have } \\
\text { been edited in line with the requirements } \\
\text { of yourself and the first reviewer to make } \\
\text { the flow more succinct. } \\
\text { Please note that the following details have } \\
\text { been removed from the data analysis } \\
\text { section. } \\
\text { - Para } 2 \text { in page 16: In order to } \\
\text { achieve this level of investigation, } \\
\text { three stages in the process of } \\
\text { interviewing individuals about their } \\
\text { everyday experiences were deployed: } \\
\text { i) preparing for the interview and } \\
\text { understanding how a life story can be } \\
\text { beneficial; ii) guiding the person } \\
\text { through the telling of his or her life } \\
\text { story during the interview process; } \\
\text { and iii) transcribing and interpreting } \\
\text { the material or obtained data } \\
\text { (Atkinson 2002). As such, a }\end{array}$ \\
\hline
\end{tabular}




\section{ABSTRACT}

Singapore is experiencing a rapid growth in its ageing population with most of the islands' inhabitants living in high-rise apartments due to the scarcity of land. The Chinese community living in Singapore comprises the largest ethnic group and are more likely to live together under one roof in an intergenerational family grouping. Currently, there are gaps in understanding intergenerational Singapore-Chinese families and their approach to caring at home for a family member with dementia. The aim of this longitudinal qualitative study was to better understand this everyday caregiving experience. Using semi-structured biographical interviews and digital photographs to elicit family stories, five intergenerational SingaporeChinese families were visited at home for a period of between six to 15 months. Each recruited intergenerational family was treated as a 'case'. Narrative analysis of the data was applied within and between cases and resulted in the emergence of three themes that represented various dynamics in the data. The three themes were identified as: i) Family values, which is about the cultural context in which everyday care takes place, the religious beliefs and practices of the intergenerational Singapore-Chinese families and the practice of filial piety; ii) Family support, which is about everyday access to family and service networks, including the contribution of the live-in maid in caring for the family member with dementia; and iii) Family bonds, which is about the maintenance of intergenerational family relations in the Chinese family kinship system.

\section{Background}

By 2030 it is estimated that 27 percent of Singapore's resident population will be aged 65 and over with the Chinese population currently forming the largest ethnic group in the country (Singapore Department of Statistics 2018; United Nations 2017). The prevalence of dementia in Singapore is increasing in tandem with the ageing population (Singapore Department of 
Statistics 2012) and, according to a recent nationwide study by Subramaniam et al. (2015), currently one in 10 people aged 60 and above in Singapore have dementia.

Owing to the limited land-mass and high-density population, approximately 85 percent of Singaporeans live in high-rise apartments (Thang and Mehta 2009) and, in these buildings, most older Singapore-Chinese people living with dementia are co-habiting at home with their intergenerational families, mainly their spouse, children, children in-law and grand-children (Singapore Department of Statistics 2009; Thang and Mehta 2009; Yap and Seng 2009). The cultural and moral values derived from the key elements of filial piety determine the caregiving experience of intergenerational Singapore-Chinese family caregivers (Dai and Dimond 1998). Hsueh (2001) conceptualised filial piety as four key elements: concern for parental health; financially supporting parents; fulfilling the housing needs of parents; and respect for parental authority. These cultural elements essentially shape intergenerational Singapore-Chinese adult children's attitudes and behaviours toward their parents, thereby ensuring the continuation of parental well-being (Sheu 1997) - including in the presence of a dementia (Koo and Pusey 2018). It is also this family-centred cultural element that ties children into sacrificing their self-interests physically, financially and socially for the benefit of their parents - or family - as a filial responsibility (Dai and Dimond 1998). This is the core foundation of a typical intergenerational Singapore-Chinese family comprising several generations co-habiting together under one roof or living in separate households (Thang and Mehta 2009).

Presently, very little is known about the everyday experiences of intergenerational SingaporeChinese families and how care is organised and supported by the intergenerational members to a family member living with dementia. Furthermore, whilst no local studies in Singapore 
have explored filial piety and its impact on the intergenerational Singapore-Chinese caregiving experience in dementia, the basis of this direction is supported by a study on Canadian-Chinese caregivers of people with dementia (Ho et al. 2003). Moreover, in Singapore, families are obligated to care as a result of national government policies that are structured and implemented along the lines of filial piety. A visible outcome of this approach is seen in the Parents' Maintenance Act (Singapore Government 2018) that ensures continued financial support of older people (including those living with dementia) from adult children (see also: Mehta 2006).

In order to manage time and competing family/work demands, a common solution to these everyday challenges and policy requirements is for most Singapore-Chinese families to employ a live-in maid - who is usually from the Philippines, Indonesia or Myanmar (Seow and Yap 2011) - to provide care at home for a person with high dependency needs. This is confirmed by a local study in Singapore which showed that, typically, one in every six households with caring responsibilities will employ a live-in maid (Thang and Mehta 2009), although this figure rises to one in every two families where a person with dementia is living at home (Tew et al. 2010; Yap and Seng 2009). The live-in maid, who is mainly female, is usually regarded as an 'extra pair of hands' in the family caregiving setting (Thang and Mehta 2009). Apart from performing the household chores, the live-in maid will also attend to the physical caregiving of the person living with dementia whilst the children mainly provide financial support and make the caregiving decisions (Ha et al. 2018; Tam et al. 2018). In view of the existing residential structures, the live-in maid and the person living with dementia sometimes rotate and stay in the homes of different intergenerational children (Seow and Yap 2011). For smaller families, the live-in maid may be the only person staying 
with, and caring for, the person living with dementia in a one or two room high-rise apartment (Seow and Yap 2011; Tam et al. 2018).

On a broader footing, the literature looking at intergenerational family care to a person living with dementia at home is immature, especially when that intergenerational care is provided under one roof. This is because the overwhelming majority of studies in family care in dementia are dyadic in nature no matter what the relationship being studied; for example, daughter to parent with dementia in a study on Canadian-Chinese carers of persons with dementia (Ho et al. 2003). In intergenerational research, there is also the thorny issue of ascertaining what comprises 'a family' in contemporary society as the boundaries are becoming increasingly blurred and influenced by issues such as divorce, second/third marriages (Sherman and Boss 2007), geographical location and Westernisation (see for example: Rolland 2012; Roach et al. 2013).

In some non-Chinese cultures, caregiving provision for a person living with dementia is drawn along gender lines. For instance, in a Maltese study by Innes, Abela and Scerri (2011) involving husbands $(n=2)$, wives $(n=2)$, daughters $(n=8)$, son $(n=1)$, daughters-in-law $(n=3)$, the findings revealed that daughters and daughters-in law were expected to provide physical care whilst the men took control of the decision-making. Developing this point further, a daughter caring for her mother in the study shared that she was told by her brothers of her obligation - as a daughter - to assume the caregiving role. Moreover, the study appears to suggest that the Maltese men continued to maintain previous interests and were able to rationalise limitations in their caregiving role with the need to maintain active social lives (Innes, Abela and Scerri 2011). A similar gender-based divide in care provision was shared in an Australian study by Boughtwood et al. (2011). 
An intergenerational qualitative study by Szinovacz (2003) from the United States of America on African-American and Caucasian White caregivers found that adolescent caregivers were more empathetic and respectful of the caregiving parent when they genuinely understood the stress their parents were undergoing. The study also reported that joint involvement in caregiving enhances adolescent-parent bonds.

In contrast, a cross-sectional intergenerational study by Hamill (2012) found that parents' influence on their children's involvement in caregiving was not determined by the degree of affection which their children have for them, but, instead, on the affection for grandparents living with dementia. Consequently, caregiving can lead to deterioration in family relationships and poor bonding in some intergenerational families resulting in unfavourable consequences, such as institutionalization of the care recipient and burden of the caregiver (Koo and Pusey 2018). Reflecting upon these studies, it is likely that the cultural context/environment in which caregiving is provided is dissimilar to that of the SingaporeChinese population. Moreover, the participants may not be intergenerational family members from the same family unit and therefore not fully representative of the actual relationship, such as how care is organised and supported by the multiple intergenerational members who are living together under one roof.

Perhaps unsurprisingly given the limited extant literature, a vacuum of understanding exists from an intergenerational Singapore-Chinese perspective, especially as the majority of care will be provided under one roof to a family member living with dementia. To take an early step to address this knowledge deficit, the primary aim of this study was to work collaboratively with intergenerational Singapore-Chinese families and the multiple intergenerational members from each of these families to understand how care for a family 
member with dementia is provided under one roof. We took a deliberate decision at this time to view a family as related kin (as operationally defined in the study inclusion criteria, shared under the next heading), rather than automatically assume that the intergenerational family would position a live-in maid (should one exist) as a member of their family. However, before moving on to consider these substantive issues, it is important for us to say that the research team was interested in the person living with dementia taking an active part in the research study and visible within their family system. Unfortunately, it was made clear by the site of recruitment at the time of first contact that this would not be possible owing to the organisation's fear of emotional harm coming to the person living with dementia should they consent to participate in the study. This organisational protectionism was reminiscent of the psychosocial research agenda in the United Kingdom in the 1980s and most of the 1990s that routinely excluded people with dementia from studies on similar grounds (Keady 1996; Keady, Williams. and Hughes-Roberts 2007). That said, to the best of our knowledge, this is the first time that a longitudinal qualitative study in intergenerational family care and dementia has been undertaken in Singapore and is therefore presented with this caveat in mind.

\section{Methods of Study}

\section{Participants and setting}

Intergenerational families were recruited from an English language and Chinese language caregivers' support group that was run by the Alzheimer's Disease Association (Singapore). Recruitment took place between March to November 2015 with the following inclusion criteria applied to the sample selection: i) immediate family member(s) who may include the spouse, children, children in-law, step children, step children in-law, sibling, nephew, niece, grandchildren or others who are related by blood, marriage or adoption; ii) an 
intergenerational Singapore-Chinese family of at least two intergenerational family caregivers residing with a person living with dementia in a single household/family unit; iii) literate in English, Mandarin or dialects; iv) aged 12 years and above; and v) providing regular care or assistance to a person living with a diagnosis of dementia. Following a series of meetings between the first author (MY-K) and staff at the Alzheimer's Disease Association (Singapore) to explain the project, its aims and inclusion criteria, staff at the facility agreed to approach suitable carers with an information pack and 'reply to' contact details of the first author. By following this approach, nine reply slips from interested family members were returned; of this number, three failed to meet the study inclusion criteria and one family withdrew shortly after commencing the study. As the data was shared between the UK and Singapore, permission to conduct the study was obtained from The University of Manchester ethics committee and, separately, Nanyang Polytechnic's Institutional Review Board. All data collection took place in Singapore.

\section{Sample}

A total of five intergenerational families providing care for a family member with dementia were recruited to the study and the summary of recruited participants is presented in Table 1, together with the research contacts per family. In keeping with the research protocol, all names are fictitious and Western names have been ascribed to all participants to cater to the wider international audience who may have difficulty following the flow of the text if Chinese sounding names are used/spelt out in text. The person living with dementia is identified with a * against their name throughout the article and all information relating to the person living with dementia was shared by the family carers who participated in the study. 
The mean age of participating intergenerational family members at entry into the study was 48 years $(\mathrm{SD}=16.53)$, the range was 19 to 65 years. As presented in Table 1 , the nine participating intergenerational family members comprised of: four daughters; two sons; one son-in-law; and two grandsons. As these relationships indicate, four of the intergenerational family members were female and five were male. Seven intergenerational family members were engaged in various forms of full-time or part-time employment and two participants were students. All intergenerational family members of the sample indicated their ethnicity as 'Singapore-Chinese.' A pencil sketch of each of the participating intergenerational families is shared below to further illuminate the data.

Family 1 comprised Olive (youngest and only daughter), Pete (second and youngest son) and *Angel (person living with dementia). The family relied heavily on their live-in maid to meet *Angel's daily care needs. They were a mainly Chinese, English and dialect speaking family with Buddhism-Taoism as the focal religion. This lower middle-income family resided in a three-room Housing and Development Board high-rise apartment. *Angel had been widowed since her 50s and had late-moderate stage vascular dementia. She was wheelchair bound and totally dependent. *Angel's eldest son resided on the fifth floor of the high-rise apartment with his own family comprising his wife, son and a daughter.

Family 2 comprised Clive (son-in-law), Joy (youngest daughter), Kit (grandson) and *Dolly (person living with dementia). They were a mainly Chinese and dialect speaking family with Buddhism-Taoism as the focal religion. This middle-income family resided in a five-room Housing and Development Board high-rise apartment. The family had lived here for about 13 years at the point of entry into the study. ${ }^{*}$ Dolly, widowed since her 70 s, had a diagnosis of early stage vascular dementia. *Dolly's two other children - an older son and daughter - had 
migrated overseas with their families several years ago. *Dolly had been staying with Clive, Joy and Kit for 20 years.

Family 3 comprised Ben (only son) who lived with his wife and only son. The family relied on their two live-in maids to meet *Pam's (person living with dementia) activities of daily living. They were a mainly English speaking 'Peranakan' family with Christianity as the focal religion. This upper middle-income family resided in a double storey semi-detached house. *Pam was widowed when she was 60 years old and had a diagnosis of late-stage Alzheimer's disease. She was wheelchair bound and totally dependent. *Pam had been staying with the family for 34 years.

Family 4 comprised Ellie (eldest daughter) who lived with her sister and only brother's daughter. The family relied on their live-in maid for meeting *Elaine's (person living with dementia) care needs. They were a mainly English and Cantonese speaking family with Christianity as the focal religion. This middle-income family resided in a five-room Housing and Development Board high-rise apartment. *Elaine was widowed when she was about 68 years old and had a diagnosis of late-stage Parkinson's disease dementia. She was wheelchair bound and totally dependent. *Elaine has four other children with families of their own three other daughters and a youngest son. *Elaine had been living with the family all her life except for the two years when she stayed with Ellie's only brother and his family.

Family 5 comprised Mindy (youngest daughter) who lived with her husband, son (Shaun) and daughter who all looked after her mother *Margaret (person living with dementia). They were a mainly English and dialect speaking family with Buddhism as the focal religion. This middle-income family resided in an executive Housing and Development Board high-rise 
apartment. The family had lived in the apartment for 15 years. *Margaret was widowed when she was 38 years old and had a diagnosis of moderate stage Parkinson's disease dementia. *Margaret had four other children - an eldest son, an eldest daughter, second son and a youngest son - who were all married with families of their own. *Margaret had lived with various members of her family all her life and had been staying with Family 5 from October 2015 to the present day.

\section{Data analysis}

A narrative approach was used to study and interpret the presented data and the interrelationship between identity, self and the social world (Riessman 2008). Accordingly, narrative inquiry 'is grounded in the study of the particular' (Radley and Chamberlain 2001: 331) and facilitates exploration of in-depth caregiving experiences within case study research (Yin 2009). This is important in intergenerational family study such as this where the aim is to focus on individual experiences within the context of intergenerational family relationships. Charon (2008) goes on to explain that narrative knowledge 'provides one person with a rich, resonant grasp of another's situation as it unfolds in time' (p.9) and this level of detail facilitates an understanding about the intergenerational families providing care for a family member with dementia.

A degree of flexibility was necessary during the interview situation especially for family caregivers who wanted to be interviewed alone as space constraint within the residential apartments (which most of the intergenerational families were residing in) meant that conversations could be overheard during the interview. Also, the families determined the space in the home where the interviews ought to be conducted which further constrained the 
researcher's ability to control the research environment; however, this was a small price to pay for the richness of the data that emerged from such encounters.

Whilst a set of interview questions had been prepared to structure each encounter, the intergenerational family participants would usually take the lead in narrating what they wanted to share about their caregiving experiences, as well as sharing other artefacts, such as digital photographs from inside and around the house, helped to provide additional depth to the encounter. As the first author is fluent in the Chinese language and to ensure accurate meaning was captured during data collection, interviews were conducted in the local language (or dialect) for participants who indicated their preference in being interviewed in Chinese (Mandarin). This was done for two participants (Olive from Family 1 and Clive from Family 2). The remainder of the interviews were conducted in English. The first author transcribed all the data. For the interviews conducted in the Chinese language, and following the general guidance of Smith, Chen and Liu (2008), the Chinese audio recordings were transcribed verbatim in Chinese characters first and then 'back-translated' into English. Two independent Mandarin speaking researchers from the first author's workplace were then asked to check a sub-sample of (anonymised) transcripts against the original audio recordings to ensure that local meanings were captured in the translation subsequently used for data analysis.

Following this procedure, data across the five intergenerational families were compared and examined to uncover recurring themes. These themes were compiled and tabled in order to display the data from individual cases 'according to some uniform framework' (Yin 2009: 156) when performing cross-case synthesis in work involving case studies. Transcripts of interviews, field notes and interpretations of the digital photographs were read and analysed 
in relation to individual members of each intergenerational family, followed by the family unit itself. Once analysis of a family unit was completed, work began on the next case. Narratives were further broken down into stories to create a sense of the whole, an approach to thematic analysis recommended by Reissman (2008). In an everyday research context, this meant that transcripts were explored line-by-line and coded with reference to a particular sequence within the text. Chosen sequences could refer to a significant storyline, event, experience or issue. Coding and emergent themes were discussed by all members of the authorship. This process underpinned the cross-case analysis of the narrative data and led to the generation of three themes, namely: i) Family values; ii) Family support; and iii) Family bonds. These themes will now be presented in more detail.

\section{Findings}

\section{Theme i): Family values}

Family values is strongly influenced by the cultural context in which care takes place, the religious beliefs and practices of the intergenerational Singapore-Chinese families and the practised value of filial piety which dictates respect for one's eldest relative. For these participating intergenerational families, therefore, family values were part and parcel of being culturally Chinese in which a combination of Buddhist, Taoist and Confucian beliefs further reinforced this deeply traditional value. Across the data set, nature and objects held significant traditional cultural meaning and values in everyday care and living together. For example, fish was symbolic for surplus, abundance and wealth and signified one of the 'eight Buddhist symbols of good fortune'. Different types of fishes symbolized a different set of meanings. A pair of golden carp symbolized love, domestic felicity, partnership, tenacity, fertility, renewal and abundance. A red or black coloured Koi fish signified success and wealth. In contrast, a peacock symbolized dignity, beauty, luck and fame, and was regarded as 'the heavenly phoenix on earth'. For the flower, branch and leaf, an odd number was 
preferred as it was meant to convey the dynamic irregularity of the life force. Unopened buds were always included among blooming flowers, as they represented life's continuous journey. The Peony flower symbolized beauty, rank, higher social status, luxury and opulence.

A set of acrylic paintings completed by Clive from Family 2 (see Table 2) is presented as a visual illustration of this practice in an everyday caring and living together context, and to explain the symbolism a little further:

\section{INSERT TABLE 2 ABOUT HERE}

- Painting 1 is a presentation of two peonies with leaves drawn in a heart shape, accompanied by three Chinese carps and set against a golden peacock. Clive shared in the interview that he was "very particular with the number of leaves drawn as an even number could potentially mean misfortune" (third interview with Clive).

- Painting 2 of an Arowana fish, also called 'Kam Lung Yue' in Chinese-Cantonese, meaning Golden Dragon Fish, was drawn by Clive for Kit. The Chinese characters on the fish's forehead mean "lifelong learning and accumulation of knowledge" (third interview with Clive) and were meant to ensure a smooth journey for Kit's coming university studies. Clive also believed that the fish would endow the family with "good luck and prosperity" (third interview with Clive).

- Painting 3 is a symbolic painting of Chinese Mandarin oranges, sunrise and Chinese Koi fishes. The oranges symbolise a happy occasion; the "sunrise symbolizes a new 
beginning every day and the fishes symbolize prosperity and abundance" (third interview with Clive). This particular painting was strategically hung on the wall facing *Dolly's bed, so that she could "see it daily upon waking up" (third interview with Clive).

- Painting 4 of a Chinese Koi fish was hung on the wall between the master bedroom (Clive and Joy's) and *Dolly's bedroom, with well-intended symbolic meaning to the bedroom occupants. Another major purpose of these symbolic paintings was to "create a familiar environment" (third interview with Clive) for *Dolly in preparation for a planned house move the following year.

Across the data set, these symbolic forms were not just 'for show' in the families' homes, but, rather, were a constant reminder to the intergenerational family members of their shared Chinese cultural heritage and that they (as an individual) were a valued member of the family. Moreover, there was a significant presence and influence of Taoist and Confucian beliefs and practices across the five families, regardless of their professed religion. This was in relation as to how the families have lived together and cared for one another in a shared space. For instance, Taoists worship many different gods (or deities), believe in respecting heaven, worshipping ancestors, a spiritual world existing in parallel with the world we live in and being compassionate to all under the 'heavens'. The combination of such beliefs, the 'Yin' and 'Yang' element of opposites complementing each other, respecting the heavens and ancestral worship worked to connect the intergenerational members of the five participating families together. In addition, the intergenerational family members from the five families prayed for each other; for example, the grandson Shaun in Family 5 prayed to Buddha for the wellbeing of his entire family, as he explained: 
"I mean that's what religion is for right? People praying. Ask for something higher order. I don't know. I always wish say... wish that... make sure everything is ok, you know. Like when I pray, I always hope that my grandma's ok. My mom's ok. My dad's ok. My sister's ok. My friends are ok [Laughs]. I'm ok. Yeah. So, my grandma is part of my wishes". (first interview with Shaun)

What was also strikingly similar across the five participating families and their values was the element of Confucian respect for their elders - filial piety and reciprocity - albeit represented in different ways. In two of the families (Families 1 and 5), ancestral worship, or veneration, was a prominent element of filial piety in their household. During interviews, this element of the Chinese traditional religion centred on the ritual celebration of their 'deified ancestors' as Confucianism requires the living to pay respect to one's ancestors, an aspect of filial piety. Prayer was usually performed at the household altar in a designated part of the house containing the ancestral tablet of their ancestors or deceased relatives. This practice served to connect together the families' internal support network, both living and deceased.

Analysis across the data set also revealed a deep sense of filial piety for other reasons. For instance, with Family 1, the youngest son Pete took charge of the family prayer altar, a role he automatically assumed after his mother *Angel was diagnosed with dementia. *Angel's daughter Olive shared the following straightforward summary about her understanding:

"It's a sense of filial piety. We have been living together all this while. My mom was the one who had been looking after me. She cared for me when I was sick." (third interview) 
On the other hand, Pete, whilst obviously affectionate towards his mother, qualified these filial statements by saying how difficult it was to see his mother living with dementia and the 'changes' that had taken place with her in recent years: "very painful" (first interview).

In Family 3, the only son Ben shared that his Christian faith emphasised the importance to "honour thy father and mother" (first interview), a value similar to Confucianism, and offered this as a primary reason for caring at home for his mother. Moreover, Mindy, the youngest daughter in Family 5, felt that filial piety was an essential part of the Chinese culture, as she shared:

"We are Chinese. I always think that, you know, Chinese, even my mother. We have to be filial." (sixth interview)

Mindy also recited the "24 Exemplars of Filial Piety" (sixth interview) which is cited in Jordan (1986), and Shaun, the grandson living in the same household, stated that:

"We are an Asian family. I mean she's my grandma, right? So, she's a member of the family. I can't just like let her be like this. So, we have to do this kind of stuff. And my mum brought me up. Everyday she takes care of me. So, I have to do the same for her next time. I try my best ... I try to relieve the burden of my mum." (first interview)

Filial piety was intertwined with a Singapore-Chinese identity and was closely observed and adhered to by the intergenerational family members taking part in this study. 


\section{Theme ii): Family support}

Family support for the person living with dementia was drawn from a number of sources, including the intergenerational family's internal support network comprising the immediate and extended family, and their external support network comprising the community and other support services, such as those provided by the Alzheimer's Disease Association (Singapore) and the live-in maid (where one was employed). However, before support could be opened up as a legitimate topic in its own right, families spoke of the difficulties they had gone through in obtaining a diagnosis of dementia for their relative. This was not so much in relation to the memory clinic and the provided service, but more in navigating and negotiating within the immediate and extended family in order to 'open up' the failing cognition/behaviours and actions of their family member with (suspected) dementia to the outside world. Reaching agreement to do this when there was opposing family views caused stress and friction in the intergenerational family that was palpable in the interviews and rippled down the years. To take but one example, in Family 1, Olive's brothers were of the opinion that little, or nothing, could be done for their mother when *Angel's memory lapses first presented. They were outwardly unsupportive and obstructive towards Olive when she wanted to seek medical help for her mother. As Olive shared, her brothers believed that if their mother was diagnosed with dementia then it would be a "waste of money" (Olive's words) as the condition is irreversible and not worth the financial outlay to find out what's wrong. Similarly, in Family 5, Mindy's siblings believed that *Margaret's cognitive changes were due to the normal ageing process rather than dementia and, as Shaun shared "the other camp always believe that my grandma is depressed!" (first interview).

Although the timeliness of intergenerational family support to seek a diagnosis was of crucial importance, obviously, in the reported study, this transition had already been accomplished 
with various levels of family agreement/conflict. However, irrespective of this, all participating intergenerational family members in the study expressed a desire for their extended intergenerational family members, such as their (other) siblings, to take a more active role as Ellie (Family 4) succinctly put it when referring to one of her sisters: "She can go all the way to Cambodia and take care of the elderly but at home, she don't take care" (second interview). Some of the female interviewees also shared that traditional perceptions of gender-specific support still remained an expectation. This was particularly evident in Family 1 when Pete (youngest son) suggested that Olive (youngest daughter) should take on care of their mother as she was the unmarried daughter: "You are currently the one staying with mom, also unmarried ... therefore the responsibility is on you!" (second interview with Olive). Similarly, Mindy, from Family 5, had hoped that her eldest sister and second brother (who did not consent to take part in the study) would provide support by sharing the caring duties instead of letting her shoulder the majority of the responsibilities: "Like I wish that they can come and go together with me." (fourth interview).

In addition, the data identified that the two grandchildren in the data set, Kit (from Family 2) and Shaun (from Family 5) played a vital role in caring whilst still studying at school. For example, Clive, Kit's father, stated that he held "no expectations" that his son would help with his grandparent's care and wanted Kit to succeed at school and in further education "above everything else." Interestingly, Kit did not fully share this aspiration and wanted to support his parents in their caring duties, as this slice of data attests:

"So, I help my father print the music notes and things to draw. Then, help convert the songs online to his mobile phone to play the songs for grandma. I just want to help my 
father. For the pictures that go with the song, he will search online from Google. Then, I will help him to print them out." (first interview)

In Family 5, Mindy's son Shaun, created a 'blog site' for his mother so that she could write about her feelings and share with others the satisfactions and stresses of her caring experiences:

"I know she has this blog. Instead of telling me, she can tell somebody on the internet. I don't expect her to tell the whole world." (first interview with Shaun)

Moreover, digital photographs and videos were accessed by the younger family members to help compile family stories that could act as reminiscence material for their relative with dementia. The study also revealed a pervasive use of information and communication technology by the families to connect with their immediate family members, as well as to obtain and receive information on dementia to support their caring activities:

"We had to check the internet for information. Not anxious but in a relaxed manner, searching for ways to help her [*Dolly]. Because things which the doctors have told us are perplexing. Why is it that the medications prescribed for her can cause all those side-effects?" (third interview with Clive)

Away from their immediate and extended families, participants were often reliant on their external support networks for everyday assistance. For instance, Families 1, 3 and 4 employed a live-in maid to help with the care for their relative with dementia and had taken this decision for a number of reasons such as feeling 'uncomfortable' when dealing with their parent's intimate care needs as Ben, from Family 3, shared: 
"Most of the activities of daily living would be handled by them [referring to the live-in maid]. I cannot handle it. Firstly, because I'm male [chuckles]. So I can't do bathing or changing clothes. And, it's not fair to my wife to do it either. So, they have to handle it." (sixth interview with Ben)

Drawn from the wider data set, other cited reasons for employing a live-in maid included the personal health issues of intergenerational family members and having to work full-time.

Perhaps unsurprisingly, given the recruitment strategy for the intergenerational carers taking part in the study, the Alzheimer's Disease Association (Singapore) and its carer's support group was also identified to be an important external support network. In particular, the support group enabled family carers to share practical tips and advice with one another, as Olive (from Family 1) shared:

"I learnt a lot of information from the caregiver support group and when I returned home, I see how to handle things better. For example, recently I saw my mother's dental problem and I was able to know how to handle it from another caregiver. Now, I also know about things to pay attention to at the advanced stage of the dementia.' (sixth interview)

However, most participants said that they were only made aware of the Alzheimer's Disease Association (Singapore) and its range of support services once a formal diagnosis of their family member with dementia had been made. 


\section{Theme iii): Family bonds}

Strong family bonds ensure the maintenance of intergenerational family relations in the Chinese family kinship system. As the data indicated, it is through these strong family bonds that the immediate and extended family connect across households to provide social and economic support, such as shared labour, socialization of the children and support for the older person living with dementia. That said, the strength of the kinship tie in the motherdaughter relationship appeared resilient throughout the data set. For example, in Family 1, Olive, the only filial daughter and youngest in her family, had always resided with, and been very close to, her mother, *Angel, as she shared:

"Because the mother-daughter kinship bond has developed over so many years. It's not easy to terminate this bond. Not so easy. I find it very difficult to do so!" (fourth interview)

Similarly, Joy was very close to her mother, *Dolly. They had been living together before and after Joy was married and started a family of her own. Joy and Clive took a photograph of this closeness to share in the interview situation, and is shared in the following photograph:

\section{INSERT PHOTOGRAPH 1 ABOUT HERE}

Ellie and her youngest sister from Family 4, who, since young, have been staying with *Elaine, also shared a very close relationship and bond with their mother. Interestingly, the mother-daughter relationship became even closer after the sisters gained a better understanding of dementia: 
"Then, my mother would, even in her late state, when she does not know anything, she would like pat my sister's face, pull the blanket over my sister. That kind of closeness." (sixth interview with Ellie)

Like Olive, Joy and Ellie, Mindy's (from Family 5) close relation with her mother, *Margaret, never once waivered even when challenged by the issues arising from *Margaret's dementia. Moreover, Mindy, being the youngest, had always been accompanying and assisting *Margaret whenever she was needed to organise family gatherings and get-togethers. That close filial kinship relation and devotion was succinctly described by Shaun:

“And, my grandma is my mom's life, you know. My mom is just taking care of her. My mom has nothing else but take care of my grandma." (first interview with Shaun)

The nature of the kinship tie related to the mother-son relation was a little different in that it was not as emotionally and physically intimate. Interestingly, when Ben from Family 3 was asked about his relationship with his mother, *Pam, he shared:

"Of course she dotes on me. I'm the only child. But I don't talk much to her. I mean, boys." (second interview)

For Ben, it was a sense of duty, his religion and pragmatism which compelled him to care for *Pam in a relational and reciprocal manner. In contrast, Pete, from Family 1, would often display affection towards his mother, such as kissing her on the cheek and hugging her before 
going out and after returning home. Interestingly, Olive stated that before the onset of their mother's dementia, this physical display of affection was rarely displayed:

"Sometimes when he comes home, he does activities with 'ma ma', gives her a touch, kisses her. Last time he doesn't even touch her at all." (fourth interview with Olive)

In developing the relational dynamic, factors in maintaining the grandparentgrandchild/grandchildren kinship tie were important, such as spending regular and meaningful time together, role modelling, and observing filial piety entrusted to the grandchildren by their parents. As seen in the data, *Dolly and Kit's grandmother-grandchild relationship (Family 2) demonstrated a very close intergenerational kinship bond, one that was filled with deep respect. The following extract from the interview data with Clive reveals the closeness of this intergenerational bond:

"Because at home he regards Po Po [maternal grandmother] as a very important member. In fact, he has very little interactions with his own Ah Ma [paternal grandmother]. He has more interactions with Po Po. When he was very young, she really looked after him. Childcare, taking bus, looking after him. Therefore, his meals, everything, was cared for by Po Po. The relationship is very good." (third interview)

Additionally, and as seen under theme (i), a strong kinship bond and filial values usually determined how the grandchild regarded the grandparent with dementia. For example, grandchildren were particularly appreciative of their grandmothers who had cared for them in their younger days, as Shaun shared: "I mean she's my grandma, right? So, she's a member of the family. I can't just like let her be like this" (first interview). The parents' positive role 
modelling in the family also helped shaped the grandchild/grandchildren's attitudes and behaviours, thereby influencing the positive relationship with the grandmother. The following was shared by Kit about his parents:

"They are quite nice and patient. But sometimes, no time. So, I do what I can. Like they will arrange the medicine into the cups by servings. Then, I take time every morning, to do some exercises or do some brain puzzles. That kind of thing." (second interview with Kit)

In addition, in this study, some of the families found that doing meaningful bonding activities brought them closer together such as going out for a meal together or more mundane actions, such as arranging medication in the 'pill boxes' of the relative with dementia. For example, for Family 2, Joy shared that it was "through exercise and communication with the family members" that they "have become closer within the family" (first interview). Moreover, even the younger generation appreciated the family time together with one particular grandchild, Kit, describing that he "enjoyed spending time together with his family" (second interview). Furthermore, the time spent actually engaging in meaningful activities together have brought previously less expressive and seemingly 'distant' relationship between the person living with dementia and family carer towards one that was closer; for example, as seen in the relationship between *Angel and Pete from Family 1.

The genuine acts of concern from the family member with dementia created a sense of satisfaction and appreciation from the family members providing the care, as Clive from Family 2 shared: 
"In the morning, she is very concerned about us. In the morning when I return home tired, she saw me eating. After that, she will tell me, "You haven't eaten? Hurry up, go and eat!" She knows I need to go and sleep in a short while. Then, I said, "I bring you for a walk. Very hot. I bring you for a walk. She said, "You go and sleep first. My walk is not necessary." Her telling me all these has two aspects. Another aspect is, she cares about me. Looking at her thinking, she is satisfied with the entire care process." (fourth interview)

Likewise, the family caregivers would usually reciprocate the positive behaviour and actions of the family member with dementia as demonstrated in this shared example from Joy (from Family 2) on the considerations related to a particular meal preparation:

"For example, breakfast, we know certain food, she doesn't really like to eat and we changed to something else. If we boil something, she wants something softer right? Then, we want crunchy ones, we scoop out the crunchy ones first. Then, let the balanced ones cook longer so that we can eat the crunchy food and she can eat the softer ones. Do it together." (second interview)

Other family caregivers in the study sample also shared that their living together and involvement in the caregiving process created a sense of appreciation from one another and from other members of the extended family, as this extract from Ellie (Family 4) illustrates:

"After that, all of them do appreciate what my youngest sister and I do for my mother and I would say, we are still a very close-knit family. We care for one another and if there is any problem in our midst, we would help out in that sense. We will see what 
we can do to help out. I think it has brought us closer. Because some of our siblings are divorced. They went through hardship. So, one reason why our nephew and nieces are close to us is because we have been helping them. " (sixth interview)

This reciprocity may help to provide a better understanding about the complexities and diversity that exists in Singapore-Chinese intergenerational members living together under one roof to provide care at home for a relative living with dementia and the importance of family bonds in this cultural context.

\section{Discussion}

This article has highlighted the everyday living together and caregiving experience of five intergenerational Singapore-Chinese families living under one roof with a family member with dementia. Over a period of between six to 15 months, a total of 42 research contacts were made over the data set and a combination of biographical interviews supplemented by digital photographs (where necessary) to help provide additional meaning to phenomenon both inside and outside the home environment.

Narrative analysis of the five intergenerational cases resulted in the emergence of three themes that explained and explored the various relational dynamics in the data, namely: i) Family values; ii) Family support; and iii) Family bonds. Drawing on these three themes, the data revealed the significance of intergenerational family connections in better understanding the relational dynamics that exist in the everyday lives of Singapore-Chinese families living with, and caring for, a relative with dementia in the home setting. Such intergenerational family connections were culturally grounded and influenced by strongly held beliefs and practices. For example, these were evident across all participating families and it connected 
together the intergenerational family members to the person living with dementia regardless of their professed religion. In the data set, the families' religious devotion, beliefs and practices were notably evident with the presence of Chinese deities such as Buddha, Ji Gong, Kuan-Yin or Goddess of Mercy and God of Wealth, which were strategically placed on the prayer altar alongside the ancestral tablet in the families' homes, and during funerals - a reminder to the intergenerational family members of the spiritual faiths and beliefs which they shared and connected with. Such deities were represented in many of the supplied photographs that formed part of the data collection methods and the intergenerational family members confirmed that they were carrying on the tradition and faith because of their family's staunch beliefs. Some family members made it their obligation to assume responsibility of the family's prayer altar comprising the deities and ancestral tablet. No matter which God, the intergenerational family members and the person living with dementia shared a common spiritual connection - to pray for each other's health, safety, well-being, redemption and/or salvation. Religion and spirituality have been shown to be important for families providing care to a person living with dementia (Milne and Chryssanthopoulou 2005; Gerdner, Tripp-Reimer and Simpson 2007) and this was also observed in the present study. However, in Singapore, very little research work has so far been conducted that examines the relevance of religion and spirituality among intergenerational Chinese family caregivers and how this important element has connected them together.

Intergenerational family connections were also seen in the shared spaces described in the study. Here, shared spaces moved beyond the geographical location of 'the home' and acted to connect together intergenerational family members who shared deep emotional bonds and physical contact with one another on a daily basis. These bonding connections were 'reinforced' through the many decades of shared togetherness, learning one another's 
idiosyncrasies and adapting to one another's needs. The data also revealed the presence of symbolic forms in the shared spaces and the time and effort spent by each intergenerational family member(s) performing meaningful, engaging and memorable activities together, such as in the time-consuming and elaborate artworks by the son-in-law with his mother-in-law in Family 2 (see Table 2) - artworks that connected together culture and family values. According to Hinton et al. (2008), religious and spiritually based symbolic meanings are likely key resources that caregivers (including, of course, Chinese caregivers) draw upon to shape their motivations and approach to the everyday process of their caregiving experience. Despite increasing knowledge on ethnic differences in family caregivers' experiences, the extent to which caregiver interventions are culturally tailored to address these differences remains relatively unknown (Napoles et al. 2010) and under-researched in Singapore.

Moreover, whilst living together in this shared space, the intergenerational family members in the study underwent a long-standing history of togetherness and connectedness, that is, from as early as the time of their own birth and marriage until the present day. Their shared and rich biographical history was filled with numerous memorable family events such as marriages, births, birthdays, first day at school, graduating from junior college, enrolment into National Service and university entrance; memories that stretched across two to six decades worth of occasions and events spanning adult children, children-in-law and grandchildren. So much so that the intergenerational family members would often reminisce longingly about the past as they related fond childhood memories and events that they shared with their relatives. The shared space, therefore, became a place for shared memories to be voiced across the generations. These actions extended the feelings of generational belonging and enhanced the life story of the intergenerational family, an area that is starting to increase in significance (Grøndahl et al. 2017; Kindell et al. 2014; Novy 2018). 
This closeness was evident in the intergenerational family connections that supported family togetherness. For the intergenerational family members in the study, these deep connections were not necessarily bound by blood ties, but rather it was expressed through a loving and reciprocal relationship that had come about from decades spent together and of which the caregiving act was just one more activity in a life-time of togetherness. The reciprocity shown by the intergenerational family members in this study was from their gratefulness and repayment of what the person with dementia had done for them previously and in the present. It was a dynamic that did not stop and was not boundaried by time. As seen in the study, intergenerational family connections in the form of filial and unconditional love were expressed through embodied actions, art work, affections and spoken words.

Developing the above point further, filial piety would also determine if the intergenerational caregivers in this study were likely to use formal support services. According to Yeon and Levkoff (2001) and Sung (1998), filial obligation affects one's motivation to use formal services and, as such, the emphasis on filial obligation could well be a deterrent in family caregivers' willingness to use formal services (Yeon and Levkoff 2001). This was seen in this present study when the intergenerational families were deciding on triggering their external support network and Families 1, 3 and 4 employed a live-in maid to help with the care of their relative with dementia. However, this latter decision-making was not as straightforward as it first may appear. Whilst the shared space of the home is 'the ideal' for the older people who needs support and the live-in maid who provides it, the home is usually seen as a private and secure space that is only accessible to intergenerational family members (Teo et al. 2006; Tew et al. 2010). Moreover, Miahouakana Matondo (2012) contends that Chinese people are usually wary of 'strangers' unless the person is part of the family. Further study on this conflicting and ambivalent positioning of the live-in maid is necessary, together with a more 
robust consideration about other issues associated with this role, such as an overarching ethic of providing such care.

As observed in this study, Netto, Goh and Yap (2009) found that some caregivers feel emotionally closer to the person living with dementia and other members of the family after the onset of the condition as caregiving necessitated more frequent interactions in the relationship. In fact, in the present study, the stronger mother-daughter relational bond provided the impetus, and determination, for one daughter (Olive from Family 1) to carry on with the care at the expense of her own health, career and sibling relationships. This situation develops earlier thinking that a closer caregiver-reported relationship is associated with more satisfaction in the caregiving role (Walker, Shin and Bird 1990), a point extended to the intergenerational families in this present study. With regard to the relationship between grandchildren and grandparents who are living with dementia, only a limited number of studies exist (see for example: Beach 1997; Attar-Schwartz, Tan and Buchanan 2009; Celdrán, Triadó and Villar 2011; Celdrán, Villar and Triadó 2012; Hamill 2012; Blanton 2013; Celdrán, Villar and Triadó 2014). In developing this relational dynamic further, factors in maintaining the grandparent grandchild/grandchildren kinship tie in this present study were important, such as spending regular and meaningful time together, role modelling, and observing filial piety entrusted to the grandchildren by their parent(s). This opens up new directions for research and policy and is sensitive to a relational and dynamic construction of care as it is experienced by, and across, different generations.

\section{Study Limitations}

There are three main study limitations. First, owing to protectionist beliefs, sampling restrictions placed on the study design meant that the person living with dementia could not 
be included in this study, although family members taking part in the study did find ways of including the person living with dementia in their narrative accounts. Secondly, the cultural context in which care of the person living with dementia takes place, the religious beliefs and practices and the practised value of filial piety were based on the intergenerational SingaporeChinese families providing care for a family member with dementia. These need to be examined in other ethnic groups who are not represented in this study, to determine if the analysis from the findings is transferable. Thirdly, the nature and design of the present study limited the inclusion of the live-in maid to explore their caregiving experience and role as an external support network for the intergenerational family and person living with dementia.

\section{Conclusion}

Intergenerational family care of a person living with dementia at home is an under-researched area, both conceptually and practically. Our experience in undertaking this study is that there are rich rewards to be gained from conducting such in-depth longitudinal work and the opportunity to gain insight into the additional layers of family care and cultural affiliations that naturally arise from such connections. In particular, from the standpoint of SingaporeChinese grandchildren caring at home for a grandparent with dementia, positive experiences were seen to exist that stemmed from a deep respect for a grandmother with dementia. Moving care beyond the dyad to the (life-long) ripples that occur within and across families (however they are defined) is a next step in research and policy, and one which, we would suggest, should include the person living with dementia whenever and wherever that is possible. 


\section{References}

Atkinson, R. 2002. The life story interview. In Gubrium, J. F. and Holstein, J. A. (eds), Handbook of Interview Research: Context \& Method. Sage Publications, Thousand Oaks California, 121-140.

Attar-Schwartz, S., Tan, J.P. and Buchanan, A. 2009. Adolescents' perspectives on relationships with grandparents: the contribution of adolescent, grandparent, and parentgrandparent relationship variables. Children and Youth Services Review, 31, 9, 1057-66.

Beach, D.L. 1997. Family caregiving: the positive impact on adolescent relationships. The Gerontologist, 37, 2, 233-38.

Blanton, P.W. 2013. Family caregiving to frail elders: experiences of young adult grandchildren as auxiliary caregivers. Journal of Intergenerational Relationships, 11, 1, 1831.

Boughtwood, D.L., Adams, J., Shanley, C., Santalucia, Y. and Kyriazopoulos, H. 2011. Experiences and perceptions of culturally and linguistically diverse family carers of people with dementia. American Journal of Alzheimer's Disease \& Other Dementias, 26, 4, 290-97.

Celdrán, M., Triadó, C. and Villar, F. 2011. 'My grandparent has dementia': How adolescents perceive their relationship with grandparents with a cognitive impairment. Journal of Applied Gerontology, 30, 3, 332-52. 
Celdrán, M., Villar, F. and Triadó, C. 2012. When grandparents have dementia: Effects on their grandchildren's family relationships. Journal of Family Issues, 33, 9, 1218-39.

Celdrán, M., Villar, F. and Triadó, C. 2014. Thinking about my grandparent: How dementia influences adolescent grandchildren's perceptions of their grandparents. Journal of Aging Studies, 29, 1-8.

Charon, R. 2008. Narrative Medicine: Honoring the Stories of Illness. Oxford University Press, New York.

Dai, Y. and Dimond, M.F. 1998. Filial piety: A cross-cultural comparison and its implications for the well-being of older parents. Journal of Gerontological Nursing, 24, 13-8.

Grøndahl, V.A., Persenius, M., Bååth, C. and Helgesen, A.K. 2017. The use of life stories and its influence on persons with dementia, their relatives and staff - a systematic mixed studies review. BMC Nursing, 16, 28. https://doi.org/10.1186/s12912-017-0223-5.

Ha, N.H.L., Chong, M.S., Choo, R.W.M., Tam, W.J. and Yap, P.L.K. 2018. Caregiving burden in foreign domestic workers caring for frail older adults in Singapore. International Psychogeriatrics, 30, 8, 1139-47.

Hamill, S.B. 2012. Caring for grandparents with Alzheimer's disease: Help from the ‘forgotten' generation. Journal of Family Issues, 33, 9, 1195-1217. 
Hinton, L., Nhauyen Tran, J., Tran, C., and Hinton, D. 2008. Religious and spiritual dimensions of the Vietnamese dementia caregiving experience. Hallym International Journal of Aging, 10, 2, 139-60.

Hsueh, K.H. 2001. Family Caregiving Experience and Health Status Among Chinese in the United States. PhD dissertation. Ann Arbor, MI: UMI Dissertation Services, ProQuest Information and Learning.

Gerdner, L.A., Tripp-Reimer, T. and Simpson, H.C. 2007. Hard lives, God's help, and struggling through: Caregiving in Arkansas Delta. Journal of Cross-cultural Gerontology, 22, 4, 355-74.

Ho, B., Friedlandb, J., Rappoltb, S. and Noh, S. 2003. Caregiving for relatives with Alzheimer's disease: Feelings of Chinese-Canadian women. Journal of Aging Studies, 17, $301-21$.

Innes, A., Abela, A. and Scerri, C. 2011. The organisation of dementia care by families in Malta: The experiences of family caregivers. Dementia: the international journal of social research and practice, $\mathbf{1 0}, 2,165-84$.

Jordan, D.K. 1986. Folk filial piety in Taiwan: The twenty-four filial exemplars. In W.H. Slote (ed), The Psycho-cultural Dynamics of the Confucian Family: Past and Present. International Cultural Society of Korea, Seoul, 47-106. 
Keady J. 1996. The experience of dementia: a review of the literature and implications for nursing practice. Journal of Clinical Nursing, 5, 5, 275-88.

Keady, J., Williams, S. and Hughes-Roberts, J. 2007. 'Making mistakes': Using coconstructed inquiry to illuminate meaning and relationships in the early adjustment to Alzheimer's disease: a single case study approach. Dementia: the international journal of social research and practice, 6, 3, 343-64.

Kindell, J, Burrow, S, Wilkinson, R. and Keady, J.D. 2014. Life story resources in dementia care: a review. Quality in Ageing and Older Adults, 15, 3, 151-61.

Koo, M.Y. and Pusey, H. 2018. Photography and case study interviewing to document intergenerational family care in Singapore-Chinese families where one member is living with dementia. In Keady, J., Hyden, L-C., Johnson, A. and Swarbrick, C. (eds), Social Research Methods in Dementia Studies: Inclusion and Innovation. Routledge, London, 140-68.

Mehta, K.K. 2006. A critical review of Singapore's policies aimed at supporting families caring for older members. Journal of Aging \& Social Policy, 18, 3/4, 43-57.

Miahouakana Matondo, J.P. 2012. Cross-cultural values comparison between Chinese and sub-Saharan Africans. International Journal of Business and Social Science, 3, 11, 38-45.

Milne, A. and Chryssanthopoulou, C. 2005. Dementia care-giving in Black and Asian populations: reviewing and refining the research agenda. Journal of Community and Applied Social Psychology, 15, 319-37. 
Napoles, A.M., Chadiha, L., Eversley, R. and Moreno-John, G. 2010. Reviews: Developing culturally sensitive dementia caregiver interventions: Are we there yet? American Journal of Alzheimer's Disease \& Other Dementias, 25, 5, 389-406.

Netto, N.R., Goh, Y.N.J. and Yap, L.K.P. 2009. Growing and gaining through caring for a loved one with dementia. Dementia: the international journal of social research and practice, $\mathbf{8}, 2,245-61$.

Novy, C. 2018. Life stories and their performance in dementia care. The Arts in Psychotherapy, 57, 95-101.

Radley, A. and Chamberlain, K. 2001. Health psychology and the study of the case: From method to analytic concern. Social Science and Medicine, 53, 321-32.

Riessman, C. K. 2008. Narrative Methods for the Human Sciences. Sage Publications, Thousand Oaks California.

Roach, P., Keady, J., Bee, P. and Williams, S. 2013. 'We can't keep going on like this': identifying family storylines in young onset dementia. Ageing and Society, 34, 1-30.

Rolland, J.S. 2012. Chapter 19: Mastering family challenges in serious illness and disability. In Walsh, F. (ed), Normal Family Processes ( $4^{\text {th }}$ edition.). Guilford Press, New York, 452-82.

Seow, D. and Yap, P.L.K. 2011. Family caregivers and caregiving in dementia. The Singapore Family Physician, 137 (supplement 1), 3, 24-9. 
Sherman, C.W. and Boss, P. 2007. Spousal dementia caregiving in the context of late-life remarriage. Dementia: the international journal of social research and practice, 6, 2, 245-70.

Sheu, S. 1997. Filial Piety (Hsiao) and Filial Caregiving Experiences of Chinese Families in the San Francisco Bay Area. University of California, San Francisco. Unpublished manuscript.

Singapore Department of Statistics. 2009. General Household Survey 2005 Statistical Release 1: Socio-Demographic and Economic Characteristics. Available online at http://www.singstat.gov.sg/pubn/popn/ghsr1.html [Accessed 25 October 2018).

Singapore Department of Statistics. 2012. Singapore in Figures 2012. [online]. Available online at: www.singstst.go.sg [Accessed 25 October 2018).

Singapore Department of Statistics. 2018. Population Trends 2016. Available online at www.singstat.gov.sg [Accessed 25 October 2018].

Singapore Government. 2018. Singapore Status Online Plus. Maintenance of Parents Act (chapter 167B). Available online at https://sso.agc.gov.sg/Act/MPA1995 [Accessed 25 October 2018].

Smith, H.J., Chen, J. and Liu, X. 2008. Language and rigour in qualitative research: Problems and principles in analyzing data collected in Mandarin. BioMed Central Medical Research Methodology, 8, 44, 1-8. 
Subramaniam, M, Chong, S.A., Vaingankar, J.A., Abdin, E., Chua, B.Y., Chua, H.C., Eng, G.K., Heng, D., Hia, S.B., Huang, W., Jeyagurunathana, A., Kua, J., Lee, S.P., Mahendran, R., Magadi, H., Malladi, S., Mccrone, P., Pang, S., Picco, L., Sagayadevan, V., Sambasivam, R., Seng, K.H., Seow, E., Shafie, S., Shahwan, S., Tan, L.L., Yap, M., Zhang, Y., Ng, L.L. and Prince, M. 2015. Prevalence of dementia in people aged 60 years and above: Results from the WiSE study. Journal of Alzheimer's Disease, 45, 4, 1127-38.

Sung, K.T. 1998. An exploration of actions of filial piety. Journal of Aging Studies, 12, 36987.

Szinovacz, M.E. 2003. Caring for a demented relative at home: Effects on parent - adolescent relationships and family dynamics. Journal of Aging Studies, 17, 445-72.

Tam, W.J., Koh, G.C., Legido-Quigley, H., Ha, N.H.L. and Yap, P.L.K. 2018. 'I can't do this alone': a study on foreign domestic workers providing long-term care for frail seniors at home. International Psychogeriatrics, 30, 9, 1269-77.

Teo, P., Mehta, K., Thang, L. L. and Chan, A. 2006. Ageing in Singapore: Service Needs and the State. Routledge, London.

Tew, C.W., Tan, L.F., Luo, N., Ng, W.Y. and Yap, P. 2010. Why family caregivers choose to institutionalize a loved one with dementia: A Singapore perspective. Dementia Geriatric Cognitive Disorder, 30, 509-16. 
Thang L.L. and Mehta, K.K. 2009. The Dynamics of Multigenerational Care in Singapore. Seminar on Family Support Networks and Population Ageing. Doha, Qatar, 3-4 June 2009.

United Nations. 2017. World Population Ageing - Highlights. Department of Economic and Social Affairs, United Nations. Available online at https://www.un.org/en/development/desa/population/publications/pdf/ageing/WPA2017_Hig hlights.pdf [Accessed 20 June 2019].

Walker, A.J., Shin, H. and Bird, D.N. 1990. Perceptions of relationship change and caregiver satisfaction. Family Relations, 39, 2, 147-52.

Yap, P. and Seng, B.K. 2009. Profiling The Dementia Family Carer In Singapore. Available online at http://www.alz.org.sg/about-dementia/publications [Accessed 25 October 2018].

Yeon, K.C. and Levkoff, S.E. 2001. Culture and dementia: Accounts by family caregivers and health professionals for dementia-affected elders in South Korea. Journal of CrossCultural Gerontology, 16, 2, 111-25.

Yin, R.K. 2009. Case Study Research: Design and Methods (4th ed.). Sage Publications, Thousand Oaks, California. 
Photograph 1: Doing Chinese New Year shopping together. From the left - Joy and *Dolly (Clive took the picture in February 2015)

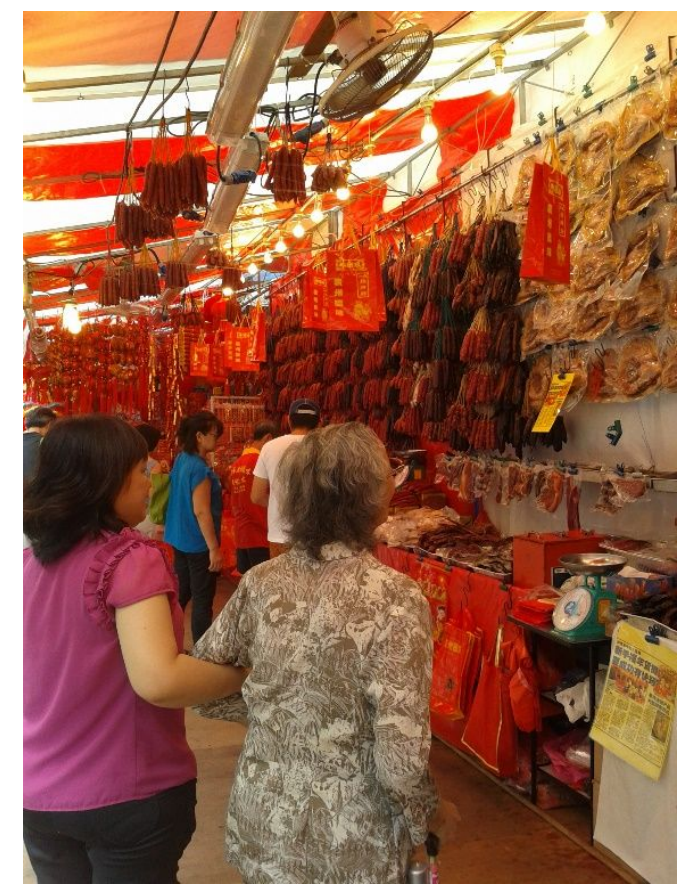


Table 1: Participant demographics and research visits

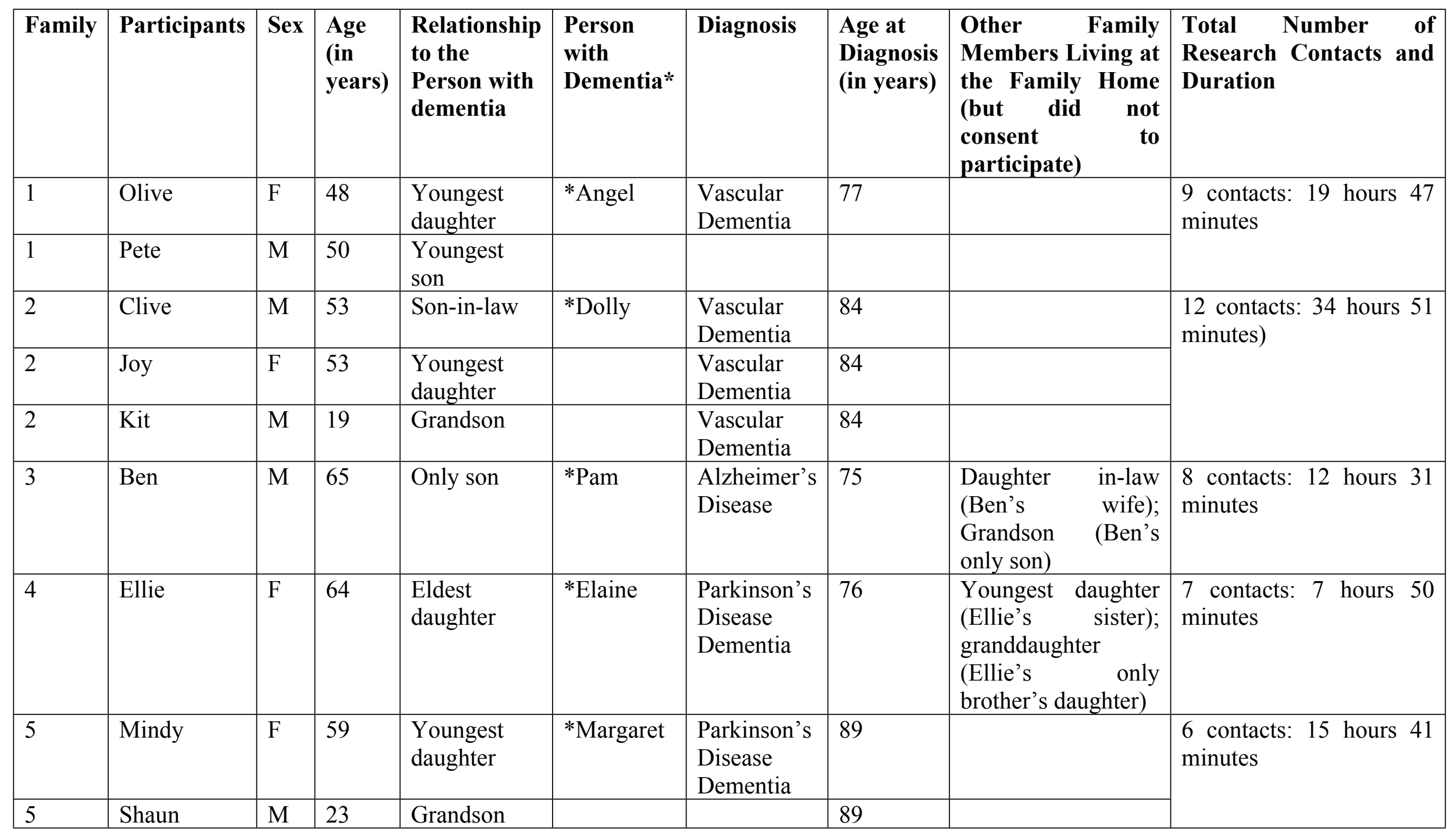


Table 2: Acrylic paintings by Clive (photographed by the first author on $26^{\text {th }}$ June 2015)

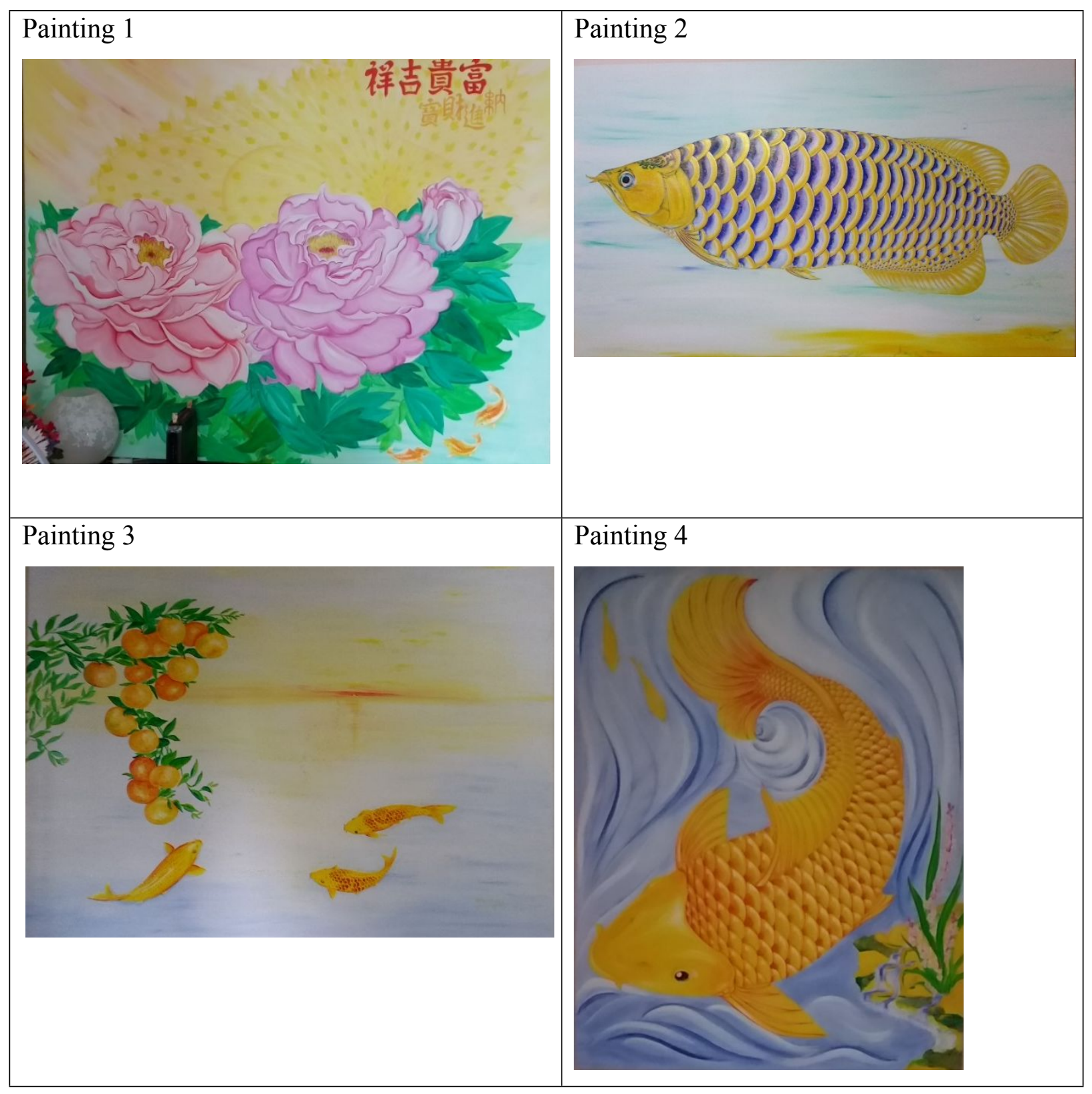

